\title{
On the hole accelerator for III-nitride light-emitting diodes
}

Zi-Hui Zhang, Yonghui Zhang, Wengang Bi, Chong Geng, Shu Xu, Hilmi Volkan Demir, and Xiao Wei Sun

Citation: Appl. Phys. Lett. 108, 151105 (2016); doi: 10.1063/1.4947025

View online: https://doi.org/10.1063/1.4947025

View Table of Contents: http://aip.scitation.org/toc/apl/108/15

Published by the American Institute of Physics

\section{Articles you may be interested in}

A charge inverter for III-nitride light-emitting diodes

Applied Physics Letters 108, 133502 (2016); 10.1063/1.4945257

Investigation of p-type depletion doping for In GaN/GaN-based light-emitting diodes

Applied Physics Letters 110, 033506 (2017); 10.1063/1.4973743

A hole accelerator for InGaN/GaN light-emitting diodes

Applied Physics Letters 105, 153503 (2014); 10.1063/1.4898588

$150 \mathrm{~mW}$ deep-ultraviolet light-emitting diodes with large-area AIN nanophotonic light-extraction structure emitting at $265 \mathrm{~nm}$

Applied Physics Letters 110, 141106 (2017); 10.1063/1.4978855

Tunnel-injected sub-260 nm ultraviolet light emitting diodes

Applied Physics Letters 110, 201102 (2017); 10.1063/1.4983352

Light extraction enhancement of AlGaN-based ultraviolet light-emitting diodes by substrate sidewall roughening Applied Physics Letters 111, 011102 (2017); 10.1063/1.4991664

\section{PHYSICS TODAY}

MANAGER'S GUIDE WHITEPAPERS
Accelerate R\&D with Multiphysics Simulation

\section{READ NOW}

PRESENTED BY

ПО $\subset$ MSOL 


\title{
On the hole accelerator for III-nitride light-emitting diodes
}

\author{
Zi-Hui Zhang, ${ }^{1, a)}$ Yonghui Zhang, ${ }^{1}$ Wengang Bi, ${ }^{1, a)}$ Chong Geng, ${ }^{1}$ Shu Xu, ${ }^{1}$ \\ Hilmi Volkan Demir, ${ }^{2,3, a)}$ and Xiao Wei Sun ${ }^{2,4, a)}$ \\ ${ }^{1}$ Key Laboratory of Electronic Materials and Devices of Tianjin, School of Electronics and Information \\ Engineering, Hebei University of Technology, 5340 Xiping Road, Beichen District, Tianjin 300401, \\ People's Republic of China \\ ${ }^{2}$ LUMINOUS! Centre of Excellence for Semiconductor Lighting and Displays, School of Electrical and \\ Electronic Engineering, Nanyang Technological University, 50 Nanyang Avenue, Singapore 639798 \\ ${ }^{3}$ Department of Electrical and Electronics, Department of Physics, and UNAM-Institute of Material Science \\ and Nanotechnology, Bilkent University, TR-06800 Ankara, Turkey \\ ${ }^{4}$ Department of Electrical and Electronic Engineering, College of Engineering, Southern University \\ of Science and Technology, 1088 Xue-Yuan Road, Nanshan District, Shenzhen, Guangdong 518055, \\ People's Republic of China
}

(Received 18 January 2016; accepted 5 April 2016; published online 14 April 2016)

\begin{abstract}
In this work, we systematically conduct parametric studies revealing the sensitivity of the hole injection on the hole accelerator (a hole accelerator is made of the polarization mismatched p-electron blocking layer (EBL)/p-GaN/p- $\mathrm{Al}_{\mathrm{x}} \mathrm{Ga}_{1-\mathrm{x}} \mathrm{N}$ heterojunction) with different designs, including the AlN composition in the $\mathrm{p}-\mathrm{Al}_{\mathrm{x}} \mathrm{Ga}_{1-\mathrm{x}} \mathrm{N}$ layer, and the thickness for the $\mathrm{p}-\mathrm{GaN}$ layer and the $\mathrm{p}-\mathrm{Al}_{\mathrm{x}} \mathrm{Ga}_{1-\mathrm{x}} \mathrm{N}$ layer. According to our findings, the energy that the holes obtain does not monotonically increase as the AlN incorporation in the $\mathrm{p}-\mathrm{Al}_{\mathrm{x}} \mathrm{Ga}_{1-\mathrm{x}} \mathrm{N}$ layer increases. Meanwhile, with $\mathrm{p}-\mathrm{GaN}$ layer or $\mathrm{p}-\mathrm{Al}_{\mathrm{x}} \mathrm{Ga}_{1-\mathrm{x}} \mathrm{N}$ layer thickening, the energy that the holes gain increases and then reaches a saturation level. Thus, the hole injection efficiency and the device efficiency are very sensitive to the $\mathrm{p}-\mathrm{EBL} / \mathrm{p}-\mathrm{GaN} / \mathrm{p}-\mathrm{Al}_{\mathrm{x}} \mathrm{Ga}_{1-\mathrm{x}} \mathrm{N}$ design, and the hole accelerator can effectively increase the hole injection if properly designed. Published by AIP Publishing.
\end{abstract}

[http://dx.doi.org/10.1063/1.4947025]

Due to the low doping efficiency for the p-GaN layer and the poor hole mobility, the hole injection for the III-nitride light-emitting diodes (LEDs) is one of the key factors limiting the quantum efficiency. ${ }^{1}$ Therefore, tremendous efforts have been made to enhance the hole injection capability. For this purpose, different designs have been proposed. It has been concluded that the p-AlGaN electron blocking layer (p-EBL) can simultaneously hinder the hole injection. ${ }^{2}$ The superlattice p-AlGaN/GaN EBL architectures have then shown the positive impact on the hole injection. ${ }^{3-5}$ The other advantage of the superlattice $\mathrm{p}-\mathrm{AlGaN} / \mathrm{GaN} \mathrm{EBL}$ is the better $\mathrm{Mg}$ activation efficiency and the higher hole concentration in the EBL. ${ }^{6-8}$ Recently, according to the report by Zhang et al., ${ }^{2}$ through adopting the valence subbands in the p-EBL, the barrier height for holes can be decreased, and this improves the hole injection across the p-EBL. Meanwhile, the removal of the p-EBL seems effective in eliminating the hole blocking, and the nEBL is proposed, which is epi-grown before the multiple quantum wells (MQWs). ${ }^{9-11}$

The hole injection can also be favored by modifying the active region. For example, researchers have suggested reducing the quantum barrier thickness, ${ }^{12,13}$ increasing the quantum well thickness along the growth orientation, ${ }^{14}$ using InGaN as quantum barriers, ${ }^{15}$ and/or using Mg-doped quantum barriers. ${ }^{16-19}$ The significance of using the GaN/InGaN structure as the last quantum barrier to enhance the hole injection has also been presented by several groups. ${ }^{20-24}$

\footnotetext{
${ }^{\text {a)} E l e c t r o n i c ~ a d d r e s s e s: ~ z h . z h a n g @ h e b u t . e d u . c n ; ~ w b i @ h e b u t . e d u . c n ; ~ v o l k a n @ ~}$ stanfordalumni.org; and sunxw@sustc.edu.cn
}

Another strategy to improve the hole injection is to increase the hole concentration in the $\mathrm{p}-\mathrm{GaN}$ layer. The ionization ratio of the $\mathrm{Mg}$ doped $\mathrm{GaN}$ layer is as low as $1 \%$ even after rapid thermal annealing. ${ }^{25,26}$ The III-nitride heterostructures possess strong polarization effect, and by employing the polarized heterostructures, Simon et al. demonstrated an enhanced p-type doping efficiency through the three dimensional hole gas (3DHG) for the nitrogen-polar GaN based LEDs. ${ }^{27}$ Later on, the 3DHG was further reported in the GaN-polar LED structures. ${ }^{28,29}$ Recently, a hole modulator is reported by Zhang et al. ${ }^{30}$ in which the p-EBL/p-GaN interface forms the two dimensional hole gas (2DHG). The 2DHG substantially increases the local hole density in the p-GaN layer and reduces the barrier height for the $\mathrm{p}-\mathrm{EBL}$.

The other method to promote the hole injection is to energize holes. Once holes obtain more energy, the carrier temperature will be correspondingly increased, and thus, the thermionic emission across the p-EBL will be more favored. We have reported the hole accelerator (see Fig. 1) to promote the hole injection. ${ }^{31}$ According to our report, we obtain that the holes can gain more energy from the hole accelerator. Experimentally, we achieved the enhanced external quantum efficiency (EQE) of $\sim 15 \%$, and the efficiency droop is reduced from $\sim 54.2 \%$ to $\sim 35.9 \%$ at $100 \mathrm{~A} / \mathrm{cm}^{2}$. However, the $\mathrm{p}-\mathrm{Al}_{\mathrm{x}} \mathrm{Ga}_{1-\mathrm{x}} \mathrm{N}$ layer in the p-EBL/p-GaN/p- $\mathrm{Al}_{\mathrm{x}} \mathrm{Ga}_{1-\mathrm{x}} \mathrm{N}$ structure can somehow cause the hole blocking effect, which makes the thickness and the AlN composition important. Thus, in this work, we numerically conduct the parametric investigations revealing the sensitivity of the hole injection on the hole accelerator with different designs. 


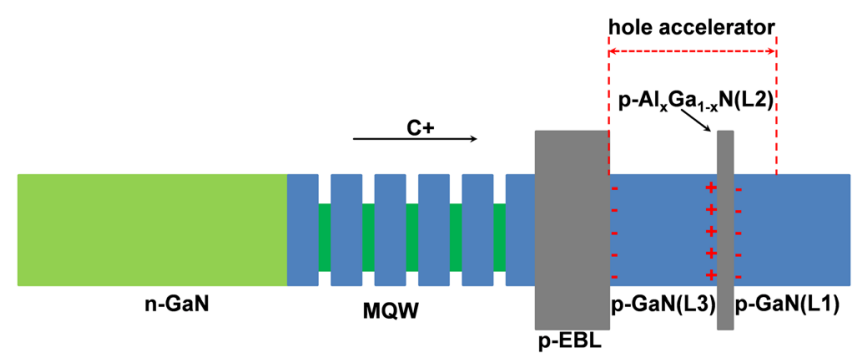

FIG. 1. Schematic energy band diagram for the InGaN/GaN LED device with a hole accelerator (layer thickness not in scale), along with which we also show the polarization induced sheet charges at L1/L2, L2/L3, and p-EBL/L3 interfaces, respectively.

The devices under study closely follow the report in Ref. [31], which consist of the $4 \mu \mathrm{m}$ unintentionally n-type GaN (n-GaN) layer, the $2 \mu \mathrm{m} \mathrm{n-GaN} \mathrm{layer}\left(\mathrm{n}=5 \times 10^{18} \mathrm{~cm}^{-3}\right)$, and the five-period $3 \mathrm{~nm}-\mathrm{In}_{0.15} \mathrm{Ga}_{0.85} \mathrm{~N} / 12 \mathrm{~nm}-\mathrm{GaN}$ MQWs. The $\mathrm{p}-\mathrm{Al}_{0.25} \mathrm{Ga}_{0.75} \mathrm{~N}$ EBL is $25 \mathrm{~nm}$ in thickness. The thickness of the p-GaN (L1) is $120 \mathrm{~nm}$. However, different from the report in Ref. 31, we change the AlN composition in the $\mathrm{p}-\mathrm{Al}_{\mathrm{x}} \mathrm{Ga}_{1-\mathrm{x}} \mathrm{N}$ (L2) layer, and the thicknesses for the $\mathrm{p}-\mathrm{GaN}$ (L3) layer and the $\mathrm{p}-\mathrm{Al}_{\mathrm{x}} \mathrm{Ga}_{1-\mathrm{x}} \mathrm{N}$ (L2) layer. The effective hole concentration in the p-type layer is assumed to be $3 \times 10^{17} \mathrm{~cm}^{-3}$. The mesa area is $350 \times 350 \mu \mathrm{m}^{2}$. The following are the physical parameters that we use: The band offset ratios for the $\mathrm{InGaN} / \mathrm{GaN}$ and $\mathrm{AlGaN} / \mathrm{GaN}$ heterojunctions are 70/30 and $50 / 50,{ }^{32}$ respectively. The Auger recombination coefficient and the Shockley-Read-Hall recombination coefficient can be found in Ref. 31. In order to reflect the polarization effect in those polarization mismatched heterojunctions, we have assumed a $40 \%$ polarization level, considering the strain release due to the dislocation generation. ${ }^{33}$ We set a constant hole mobility of $5.0 \mathrm{~cm}^{2} / \mathrm{V}$-s for both the $\mathrm{p}-\mathrm{GaN}$ and $\mathrm{p}-\mathrm{AlGaN}$ layers with the hole concentration of $3 \times 10^{17} \mathrm{~cm}^{-3}$, since neglecting the dependence of the hole mobility on the electric field will not change our conclusions in this work. ${ }^{34}$

(1) Physical parameter justification by reproducing the experimental results: We measured and numerically calculated the optical power in terms of the injection current for the LED device without using the hole accelerator, which is shown in Fig. 2. Clearly, we can see that the numerically calculated result agrees with the

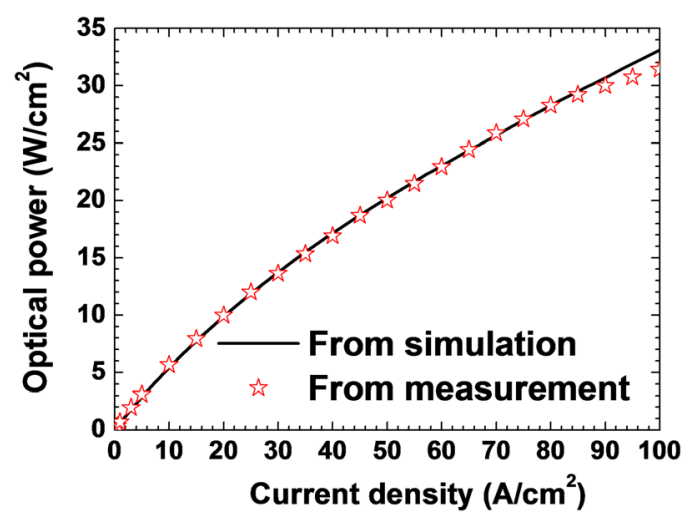

FIG. 2. Experimentally measured and numerically calculated optical power in terms of the injection current for the reference InGaN/GaN LED without the hole accelerator. experimentally measurement, which justifies the physical parameters that we set.

(2) Influence of the AIN composition: As has been mentioned, the hole accelerator makes use of the polarization induced electric field to energize holes, i.e., $V=\mu_{p} \cdot E_{\text {field }}$ and $E_{k}=\frac{1}{2} m_{h}^{*} \cdot V^{2}$, where $V$ is the hole velocity, $\mu_{p}$ is the hole mobility, $m_{h}{ }^{*}$ is the hole effective mass, and $E_{\text {field }}$ is the electric field, by which the holes are accelerated/decelerated. ${ }^{35}$ Therefore, we calculated the electric field profiles at the current density level of $86 \mathrm{~A} / \mathrm{cm}^{2}$ [see Fig. 3(a)] for the LED devices which have different AIN compositions in the hole accelerator. The AIN composition varies among $10 \%, 15 \%, 20 \%, 25 \%$, and $30 \%$. Meanwhile, the thicknesses for the $\mathrm{p}-\mathrm{GaN}$ (L3) and $\mathrm{p}-\mathrm{Al}_{\mathrm{x}} \mathrm{Ga}_{1-\mathrm{x}} \mathrm{N}$ (L2) layers are $80 \mathrm{~nm}$ and $3 \mathrm{~nm}$, respectively. The direction of the electric field is opposite to the $\mathrm{C}+$ growth orientation.

Fig. 3(a) also shows that the electric field profiles in the p-GaN (L3) layer oppose to the $\mathrm{C}+$ orientation due to the polarization induced positive charges at the L2/L3 interface and the negative charges at the p-EBL/L3 interface. In the meantime, the field intensity increases as more AlN is incorporated into the $\mathrm{p}-\mathrm{Al}_{\mathrm{x}} \mathrm{Ga}_{1-\mathrm{x}} \mathrm{N}$ (L2) layer. The electric field configuration in the p-GaN (L3) layer enables the acceleration effect to the nonequilibrium holes. Nevertheless, the electric field profiles in the $\mathrm{p}-\mathrm{Al}_{\mathrm{x}} \mathrm{Ga}_{1-\mathrm{x}} \mathrm{N}$ (L2) layer follow the $\mathrm{C}+$ orientation and this arises from the reversed polarity in the $\mathrm{p}-\mathrm{Al}_{\mathrm{x}} \mathrm{Ga}_{1-\mathrm{x}} \mathrm{N}$ (L2) layer that has the in-plane tensile strain. The electric field configuration in the $\mathrm{p}-\mathrm{Al}_{\mathrm{x}} \mathrm{Ga}_{1-\mathrm{x}} \mathrm{N}$ (L2) layer will decelerate the nonequilibrium holes. Meanwhile, further investigations into Fig. 3(a) reveal that we obtain the positive electric field in the partial p-GaN (L1) layer, which is ascribed to the negative sheet charges at the L1/L2 interface, and the electric field configuration in the $\mathrm{p}-\mathrm{GaN}$ (L1) layer also accelerates the nonequilibrium holes. Note that we also show the electric field profile for the LED device without the hole accelerator for comparison, as shown in Fig. 3(a). We now can summarize that the holes will receive more kinetic energy in the p-GaN (L3) layer and the partial p-GaN (L1) layer. However, the drift velocity of the holes will be reduced when they travel through the $\mathrm{p}-\mathrm{Al}_{\mathrm{x}} \mathrm{Ga}_{1-\mathrm{x}} \mathrm{N}$ (L2) layer.

In order to illustrate the impact of the polarization induced electric field on the hole transport, we further calculate the net work $(W)$ conducted on the holes by following $W=e \int_{0}^{l} E_{\text {field }} \cdot d x$, where the integration step $(d x)$ has been properly adjusted by optimizing the mesh distributions in the devices. The integration range starts from the p-EBL/ p-GaN (L3) interface to the relative position of $0.17 \mu \mathrm{m}$ [see Fig. 3(a)], since beyond this range the electric field profiles are identical for all the devices. The values of $W$ for all the devices are shown in Fig. 3(b). The hole accelerator is not grown if the AlN composition is $0.0 \%$. Interestingly, we can see that the work done to the holes declines if the AlN composition in the $\mathrm{p}-\mathrm{Al}_{\mathrm{x}} \mathrm{Ga}_{1-\mathrm{x}} \mathrm{N}$ (L2) layer increases from $0.0 \%$ up to $15 \%$. This indicates the impact of the polarization induced electric field in the $\mathrm{p}-\mathrm{Al}_{\mathrm{x}} \mathrm{Ga}_{1-\mathrm{x}} \mathrm{N}$ (L2) layer is dominant, and the holes will be decelerated. However, if the AlN composition in the $\mathrm{p}-\mathrm{Al}_{\mathrm{x}} \mathrm{Ga}_{1-\mathrm{x}} \mathrm{N}$ (L2) layer is beyond $15 \%$, we can obtain that the holes will receive more kinetic energy 


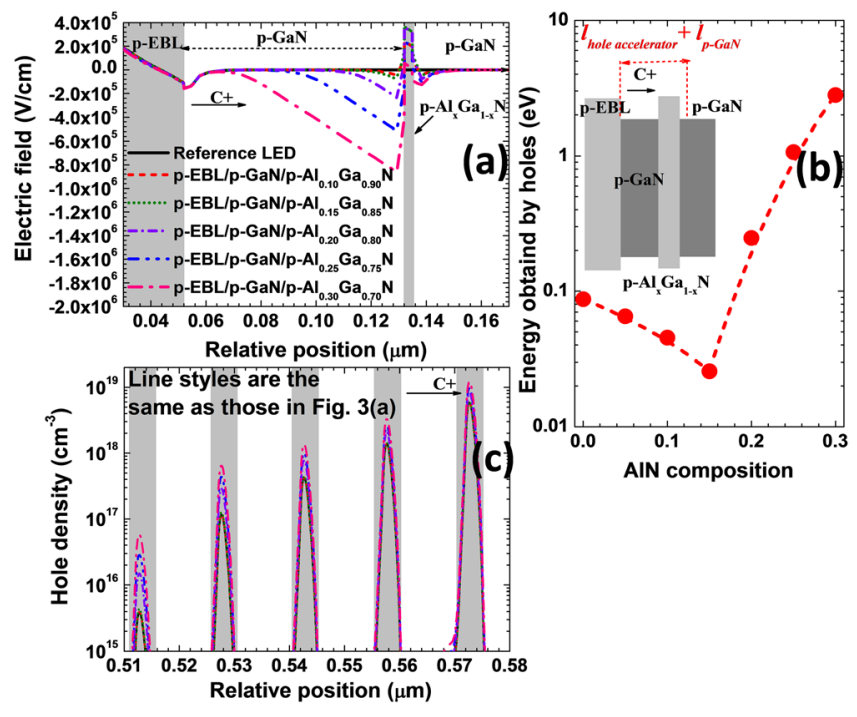

FIG. 3. (a) Electric field profiles, (b) kinetic energy obtained by holes, and (c) hole density profiles in the MQW region for the investigated LED devices with various $\mathrm{AlN}$ compositions in the $\mathrm{p}-\mathrm{Al}_{\mathrm{x}} \mathrm{Ga}_{1-\mathrm{x}} \mathrm{N}$ (L2) layer. Data collected at $86 \mathrm{~A} / \mathrm{cm}^{2}$.

from the hole accelerator with the AlN composition further increasing.

We then calculate and show the hole profiles in the MQW region for all the studied devices in Fig. 3(c). We can see that the hole density in the quantum wells is not strongly affected when the AlN composition is smaller than $15 \%$ in the p- $\mathrm{Al}_{\mathrm{x}} \mathrm{Ga}_{1-\mathrm{x}} \mathrm{N}$ (L2) layer, since the holes will not receive sufficient kinetic energy from the hole accelerator [see Fig. 3(b)]. If the AlN composition is higher than $15 \%$ in the $\mathrm{p}-\mathrm{Al}_{\mathrm{x}} \mathrm{Ga}_{1-\mathrm{x}} \mathrm{N}$ (L2) layer, the hole concentration in the quantum wells will be substantially enhanced, and more importantly, the hole injection increases as more AlN is alloyed into the $\mathrm{p}-\mathrm{Al}_{\mathrm{x}} \mathrm{Ga}_{1-\mathrm{x}} \mathrm{N}$ (L2) layer. The more efficient hole injection is due to the fact that the holes are able to receive more kinetic energy from the hole accelerator [see Fig. 3(b)].

The optical output power at $86 \mathrm{~A} / \mathrm{cm}^{2}$ for all the devices is summarized and shown in Fig. 4(a). We can see that, although the holes are not accelerated when the AlN composition is lower that $15 \%$ in the $\mathrm{p}-\mathrm{Al}_{\mathrm{x}} \mathrm{Ga}_{1-\mathrm{x}} \mathrm{N}$ (L2) layer, the optical output power does not decrease. The optical output power is significantly enhanced when the AlN composition in the $\mathrm{p}-\mathrm{Al}_{\mathrm{x}} \mathrm{Ga}_{1-\mathrm{x}} \mathrm{N}$ (L2) layer is higher than $15 \%$ according to Fig. 4(a). Besides, we plot the optical output power and the EQE as a function of the injection current density in Fig. 4(b), which also shows that the hole accelerator is able to reduce the efficiency droop when the AlN composition is higher than $15 \%$ in the $\mathrm{p}-\mathrm{Al}_{\mathrm{x}} \mathrm{Ga}_{1-\mathrm{x}} \mathrm{N}$ (L2) layer. Both
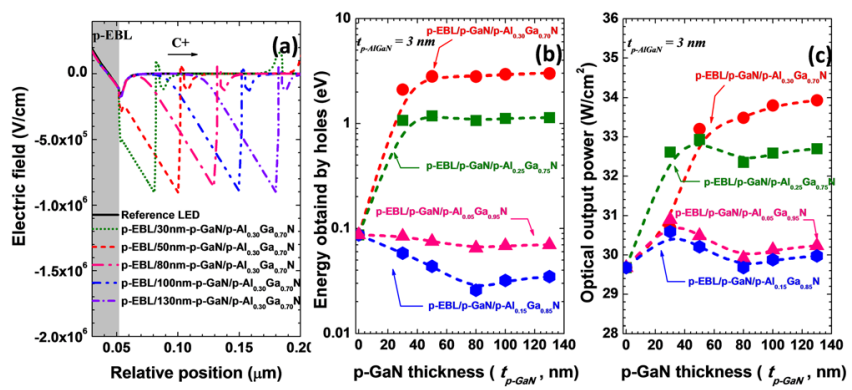

FIG. 5. (a) Numerically calculated electric profiles with various the p-GaN (L3) layer thicknesses, (b) summarized net work done to the nonequilibrium holes in terms of the p-GaN (L3) layer thickness, and (c) the optical output power in terms of the p-GaN (L3) layer thickness. Figs. 5(b) and 5(c) also employ $\mathrm{p}-\mathrm{Al}_{0.05} \mathrm{Ga}_{0.95} \mathrm{~N}$ (L2), p- $\mathrm{Al}_{0.15} \mathrm{Ga}_{0.85} \mathrm{~N}$ (L2), p- $\mathrm{Al}_{0.25} \mathrm{Ga}_{0.75} \mathrm{~N}$ (L2), and $\mathrm{p}-\mathrm{Al}_{0.30} \mathrm{Ga}_{0.70} \mathrm{~N}$ (L2) layers. Data collected at the current density level of $86 \mathrm{~A} / \mathrm{cm}^{2}$.

Figs. 4(a) and 4(b) demonstrate that the EQE and the efficiency droop are not negatively affected though the holes do not obtain the adequate kinetic energy from the hole accelerator when the $\mathrm{p}-\mathrm{Al}_{\mathrm{x}} \mathrm{Ga}_{1-\mathrm{x}} \mathrm{N}$ (L2) layer has AlN fraction lower than 15\% [see Fig. 3(b)]. We believe the better current spreading induced by the $\mathrm{p}-\mathrm{Al}_{\mathrm{x}} \mathrm{Ga}_{1-\mathrm{x}} \mathrm{N}$ (L2) barrier is useful in maintaining the hole density and optical output power at the same level despite the unaccelerated holes. ${ }^{36,37}$

(3) Influence of the p-GaN (L3) layer thickness: According to $W=e \int_{0}^{l} E_{\text {field }} \cdot d x$, the hole injection is also strongly influenced by the thickness of the p-GaN (L3) layer. We calculate and demonstrate the electric field profiles in Fig. 5(a), which adopts the p-GaN (L3) layer with the thicknesses of $30 \mathrm{~nm}, 50 \mathrm{~nm}, 80 \mathrm{~nm}, 100 \mathrm{~nm}$, and $130 \mathrm{~nm}$, respectively. The $\mathrm{p}-\mathrm{Al}_{\mathrm{x}} \mathrm{Ga}_{1-\mathrm{x}} \mathrm{N}$ (L2) layer is set to $3 \mathrm{~nm}$ and the AlN composition is $30 \%$. The electric field profile for the reference LED device without the hole accelerator is also shown in Fig. 5(a) for comparison. Fig. 5(a) indicates that holes experience the polarization induced electric field in the whole p-GaN (L3) layer when the thickness of $\mathrm{p}-\mathrm{GaN}$ (L3) layer is $30 \mathrm{~nm}$ and $50 \mathrm{~nm}$, respectively. If the p-GaN (L3) thickness is increased to the $80 \mathrm{~nm}, 100 \mathrm{~nm}$, and $130 \mathrm{~nm}$, respectively, then only the partial p-GaN (L3) layer can produce the polarization induced electric field. For example, in the relative position ranging between $0.05 \mu \mathrm{m}$ and $0.11 \mu \mathrm{m}$, the electric field intensity for the hole accelerator with the $130 \mathrm{~nm}$ thick p-GaN (L3) layer is identical as that in the reference LED device.

Fig. 5(b) shows the net energy obtained by the holes from the hole accelerator. For the designs of p-EBL/p-GaN (L3)/p-
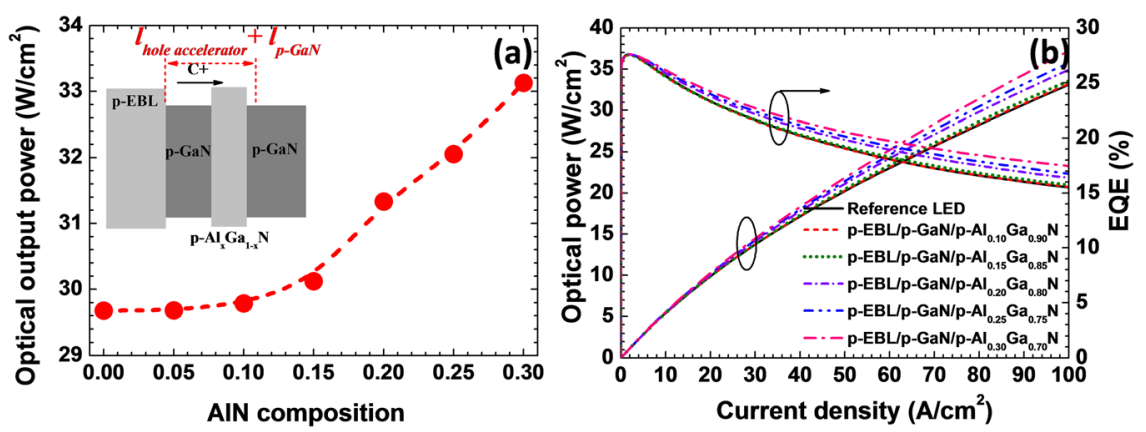

FIG. 4. (a) Optical output power in terms of different AlN alloys in the p$\mathrm{Al}_{\mathrm{x}} \mathrm{Ga}_{1-\mathrm{x}} \mathrm{N}$ (L2) layer at the current density level of $86 \mathrm{~A} / \mathrm{cm}^{2}$ and (b) optical output power and $\mathrm{EQE}$ as the function of the injection current density for all the studied LED devices. 
$\mathrm{Al}_{0.25} \mathrm{Ga}_{0.75} \mathrm{~N}$ (L2) and p-EBL/p-GaN (L3)/p- $\mathrm{Al}_{0.30} \mathrm{Ga}_{0.70} \mathrm{~N}$ (L2), the energy that holes receive first increases as the p-GaN (L3) layer thickens, since a thicker p-GaN (L3) layer enables more work than the holes obtain, and this can then inject more holes into the quantum wells (not shown here). Nevertheless, the energy reaches the saturation when the p-GaN (L3) layer thickness is beyond $50 \mathrm{~nm}$ for both $\mathrm{p}-\mathrm{EBL} / \mathrm{p}-\mathrm{GaN}$ (L3)/p$\mathrm{Al}_{0.25} \mathrm{Ga}_{0.75} \mathrm{~N}$ (L2) and p-EBL/p-GaN (L3)/p- $\mathrm{Al}_{0.30} \mathrm{Ga}_{0.70} \mathrm{~N}$ (L2) designs. According to Fig. 5(a), if the p-GaN (L3) is too thick, part of it possesses the electric field of the same magnitude as the reference LED device, thus making little contribution to energize holes. Interestingly, we can see from Fig. 5(b) that if the AlN composition is $5 \%$ and $15 \%$ in the p$\mathrm{Al}_{\mathrm{x}} \mathrm{Ga}_{1-\mathrm{x}} \mathrm{N}$ (L2) layer, the holes will not significantly increase the kinetic energy, since holes will undergo more negative work when traveling through the $\mathrm{p}-\mathrm{Al}_{\mathrm{x}} \mathrm{Ga}_{1-\mathrm{x}} \mathrm{N}$ (L2) layer.

We collect and present the optical output power in terms of the p-GaN (L3) layer thickness at $86 \mathrm{~A} / \mathrm{cm}^{2}$ in Fig. 5(c). For both p-EBL/p-GaN (L3)/p- $\mathrm{Al}_{0.25} \mathrm{Ga}_{0.75} \mathrm{~N}$ (L2) and p-EBL/p$\mathrm{GaN}$ (L3)/p- $\mathrm{Al}_{0.30} \mathrm{Ga}_{0.70} \mathrm{~N}$ (L2) designs, the optical output power is enhanced with the increasing p-GaN (L3) layer thickness. After $50 \mathrm{~nm}$, the optical power is however less dependent on the p-GaN (L3) layer thickness. Note that, when the p-GaN (L3) layer thickness is $30 \mathrm{~nm}$, the optical output power for the device with $\mathrm{p}-\mathrm{EBL} / \mathrm{p}-\mathrm{GaN}(\mathrm{L} 3) / \mathrm{p}-\mathrm{Al}_{0.30} \mathrm{Ga}_{0.70} \mathrm{~N}$ (L2) structure is lower than that for the device with the p-EBL/p-GaN (L3)/ $\mathrm{p}-\mathrm{Al}_{0.25} \mathrm{Ga}_{0.75} \mathrm{~N}$ (L2) structure, and this is due to the larger hole blocking effect at the p-GaN (L1)/p- $-\mathrm{Al}_{0.30} \mathrm{Ga}_{0.70} \mathrm{~N}$ (L2) interface. ${ }^{38}$ Furthermore, being consistent with Fig. 5(b), the optical output power is not remarkably enhanced for the devices with both p-EBL/p-GaN (L3)/p- $\mathrm{Al}_{0.05} \mathrm{Ga}_{0.95} \mathrm{~N}$ (L2) and p$\mathrm{EBL} / \mathrm{p}-\mathrm{GaN}(\mathrm{L} 3) / \mathrm{p}-\mathrm{Al}_{0.15} \mathrm{Ga}_{0.85} \mathrm{~N}$ (L2) hole accelerators, since some holes are blocked by the p- $\mathrm{Al}_{0.05} \mathrm{Ga}_{0.95} \mathrm{~N}$ (L2) layer and p- $\mathrm{Al}_{0.15} \mathrm{Ga}_{0.85} \mathrm{~N}$ (L2) layer, respectively, while those unblocked holes are not able to receive the sufficient kinetic energy for climbing over the p-EBL, which then results in the unimproved hole concentration in the MQWs.

(4) Impact of the $\mathrm{p}-\mathrm{Al}_{\mathrm{x}} \mathrm{Ga}_{1-\mathrm{x}} \mathrm{N}$ (L2) layer thickness: Finally, we investigate the impact of the $\mathrm{p}-\mathrm{Al}_{\mathrm{x}} \mathrm{Ga}_{1-\mathrm{x}} \mathrm{N}$ (L2) layer thickness on the hole injection. The same strategy has been followed that we demonstrate the electric profiles in the various structured hole accelerators in Fig. 6(a),

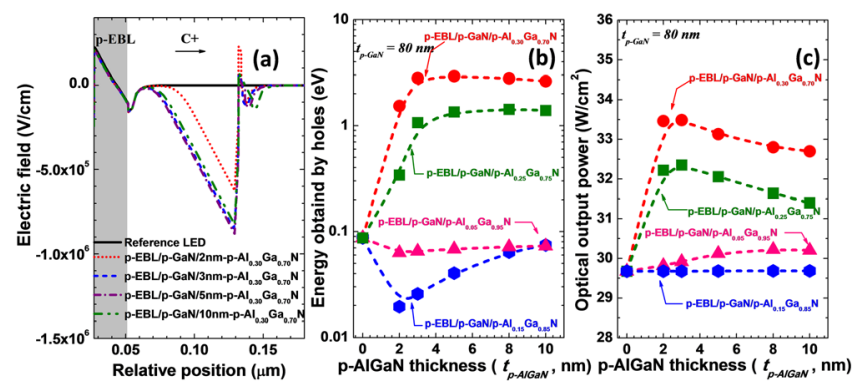

FIG. 6. (a) Numerically calculated electric profiles with various $\mathrm{p}-\mathrm{Al}_{\mathrm{x}} \mathrm{Ga}_{1-\mathrm{x}} \mathrm{N}$ (L2) layer thicknesses, (b) summarized net work done to the nonequilibrium holes in terms of the $\mathrm{p}-\mathrm{Al}_{\mathrm{x}} \mathrm{Ga}_{1-\mathrm{x}} \mathrm{N}$ (L2) layer thickness, and (c) the optical output power in terms of the p- $\mathrm{Al}_{\mathrm{x}} \mathrm{Ga}_{1-\mathrm{x}} \mathrm{N}$ (L2) layer thickness. Figs. 6(b) and 6(c) also employ $\mathrm{p}-\mathrm{Al}_{0.05} \mathrm{Ga}_{0.95} \mathrm{~N}$ (L2), p- $\mathrm{Al}_{0.15} \mathrm{Ga}_{0.85} \mathrm{~N}$ (L2), p$\mathrm{Al}_{0.25} \mathrm{Ga}_{0.75} \mathrm{~N}$ (L2), and $\mathrm{p}-\mathrm{Al}_{0.30} \mathrm{Ga}_{0.70} \mathrm{~N}$ (L2) layers. Data collected at the current density of $86 \mathrm{~A} / \mathrm{cm}^{2}$. e.g., p-EBL/p-GaN (L3)/2 nm-p- $\mathrm{Al}_{0.30} \mathrm{Ga}_{0.70} \mathrm{~N}$ (L2), p$\mathrm{EBL} / \mathrm{p}-\mathrm{GaN}(\mathrm{L} 3) / 3 \mathrm{~nm}-\mathrm{p}-\mathrm{Al}_{0.30} \mathrm{Ga}_{0.70} \mathrm{~N}$ (L2), p-EBL/p$\mathrm{GaN}$ (L3)/5 nm-p- $\mathrm{Al}_{0.30} \mathrm{Ga}_{0.70} \mathrm{~N}$ (L2), and p-EBL/p-GaN (L3)/10 nm-p- $\mathrm{Al}_{0.30} \mathrm{Ga}_{0.70} \mathrm{~N}$ (L2). Here, the p-GaN (L3) layer thickness is fixed at $80 \mathrm{~nm}$. From Fig. 6(a), we can see that the electric field intensity in the p-GaN (L3) layer increases if the $\mathrm{p}-\mathrm{Al}_{\mathrm{x}} \mathrm{Ga}_{1-\mathrm{x}} \mathrm{N}$ (L2) layer thickness is increased from $2 \mathrm{~nm}$ to $3 \mathrm{~nm}$. Then, the electric field is less affected even if the $\mathrm{p}-\mathrm{Al}_{\mathrm{x}} \mathrm{Ga}_{1-\mathrm{x}} \mathrm{N}$ (L2) layer is further thickened.

We then summarize the net work done to the nonequilibrium holes by different hole accelerators, which is presented in Fig. 6(b). For the p-EBL/p-GaN (L3)/p- $\mathrm{Al}_{0.25} \mathrm{Ga}_{0.75} \mathrm{~N}$ (L2) and the p-EBL/p-GaN (L3)/p- $\mathrm{Al}_{0.30} \mathrm{Ga}_{0.70} \mathrm{~N}$ (L2) accelerators, the holes originally increase the kinetic energy with the increasing $\mathrm{p}-\mathrm{Al}_{\mathrm{x}} \mathrm{Ga}_{1-\mathrm{x}} \mathrm{N}$ (L2) layer thickness before the saturation arrival at $3 \mathrm{~nm}$. We can also obtain the fact that the pEBL/p-GaN (L3)/p- $\mathrm{Al}_{0.30} \mathrm{Ga}_{0.70} \mathrm{~N}$ (L2) accelerator can provide more energy for holes than the $\mathrm{p}-\mathrm{EBL} / \mathrm{p}-\mathrm{GaN}$ (L3)/p$\mathrm{Al}_{0.25} \mathrm{Ga}_{0.75} \mathrm{~N}$ (L2) structure. Moreover, the holes are not able to receive the sufficient energy from the hole accelerators with the p-EBL/p-GaN (L3)/p- $\mathrm{Al}_{0.05} \mathrm{Ga}_{0.95} \mathrm{~N}$ (L2) and the pEBL/p-GaN (L3)/p- $\mathrm{Al}_{0.15} \mathrm{Ga}_{0.85} \mathrm{~N}$ (L2) designs.

The optical output power in terms of the $\mathrm{p}-\mathrm{Al}_{\mathrm{x}} \mathrm{Ga}_{1-\mathrm{x}} \mathrm{N}$ (L2) layer thickness for all the studied devices is illustrated in Fig. 6(c). For the p-EBL/p-GaN (L3)/p- $\mathrm{Al}_{0.25} \mathrm{Ga}_{0.75} \mathrm{~N}$ (L2) and the p-EBL/p-GaN (L3)/p- $\mathrm{Al}_{0.30} \mathrm{Ga}_{0.70} \mathrm{~N}$ (L2) structures, the optical output power increases with the increasing $\mathrm{p}-\mathrm{Al}_{\mathrm{x}} \mathrm{Ga}_{1-\mathrm{x}} \mathrm{N}$ (L2) layer thickness. However, when the p$\mathrm{Al}_{\mathrm{x}} \mathrm{Ga}_{1-\mathrm{x}} \mathrm{N}$ (L2) layer thickness is $3 \mathrm{~nm}$, further increase in the $\mathrm{p}-\mathrm{Al}_{\mathrm{x}} \mathrm{Ga}_{1-\mathrm{x}} \mathrm{N}$ (L2) layer thickness will not contribute to the enhanced optical performance. On the contrary, the optical output power drops, since if the $\mathrm{p}-\mathrm{Al}_{\mathrm{x}} \mathrm{Ga}_{1-\mathrm{x}} \mathrm{N}$ (L2) layer is too thick, we have even more hole blocking effect at the L1/L2 interface. ${ }^{38}$ As has been mentioned, the AlN composition in the $\mathrm{p}-\mathrm{Al}_{\mathrm{x}} \mathrm{Ga}_{1-\mathrm{x}} \mathrm{N}$ (L2) layer is also essentially critical. If the AlN composition is not high enough, the polarization level in the p-GaN (L3) layer will not be strong. Because of that reason, the holes are not able to receive the sufficient energy from the p-EBL/p-GaN (L3)/p- $\mathrm{Al}_{0.05} \mathrm{Ga}_{0.95} \mathrm{~N}$ (L2) and the p-EBL/p-GaN (L3)/p- $\mathrm{Al}_{0.15} \mathrm{Ga}_{0.85} \mathrm{~N}$ (L2) designs, and then the optical performance is not remarkably improved.

In conclusion, we have investigated different $\mathrm{p}-\mathrm{EBL} / \mathrm{p}$ $\mathrm{GaN} / \mathrm{p}-\mathrm{Al}_{\mathrm{x}} \mathrm{Ga}_{1-\mathrm{x}} \mathrm{N}$ hole accelerators. The polarization induced electric field in the $\mathrm{p}-\mathrm{GaN}$ layer can energize the holes. However, the $\mathrm{p}-\mathrm{Al}_{\mathrm{x}} \mathrm{Ga}_{1-\mathrm{x}} \mathrm{N}$ layer can decelerate holes, thus making the $\mathrm{p}-\mathrm{GaN}$ thickness, the $\mathrm{p}-\mathrm{Al}_{\mathrm{x}} \mathrm{Ga}_{1-\mathrm{x}} \mathrm{N}$ thickness, and the AlN composition vitally important. Our studies show that various hole accelerators may also cause different hole blocking and current spreading. In this work, the hole injection is promoted if the AIN composition is larger than $20 \%$. Meanwhile, a $50 \mathrm{~nm}$ thick p-GaN layer is sufficient to energize holes while further increasing the $\mathrm{p}-\mathrm{GaN}$ layer thickness will not improve the hole injection any more. Meanwhile, the studies in this work find a too thick $\mathrm{p}-\mathrm{Al}_{\mathrm{x}} \mathrm{Ga}_{1-\mathrm{x}} \mathrm{N}$ layer will cause the hole blocking effect and thus reduce the hole injection. On the other hand, a thinner $\mathrm{p}-\mathrm{Al}_{\mathrm{x}} \mathrm{Ga}_{1-\mathrm{x}} \mathrm{N}$ layer $(3 \mathrm{~nm}$ in this study) is able to energize holes for our devices to improve 
the hole injection. Therefore, the hole accelerator is very promising in improving the quantum efficiency for the IIInitride LEDs. It shall also be noted that considering the uncertain polarization level for LED epi-wafers grown with different technologies, a reliable assessment of the hole accelerator is difficult without direct experimental measurements. However, we believe that the findings in this work offer the design principles and are hereby useful for the community to further optimize the hole accelerator.

This work was supported by Natural Science Foundation of China (Project No. 51502074).

${ }^{1}$ G. Verzellesi, D. Saguatti, M. Meneghini, F. Bertazzi, M. Goano, G. Meneghesso, and E. Zanoni, J. Appl. Phys. 114, 071101 (2013).

${ }^{2}$ Z.-H. Zhang, Z. Ju, W. Liu, S. T. Tan, Y. Ji, Z. Kyaw, X. Zhang, N. Hasanov, X. W. Sun, and H. V. Demir, Opt. Lett. 39, 2483 (2014).

${ }^{3}$ Y. Y. Zhang and Y. A. Yin, Appl. Phys. Lett. 99, 221103 (2011).

${ }^{4}$ S.-J. Lee, S.-H. Han, C.-Y. Cho, S. P. Lee, D. Y. Noh, H. W. Shim, Y. C. Kim, and S.-J. Park, J. Phys. D: Appl. Phys. 44, 105101 (2011).

${ }^{5}$ J. H. Park, Y. K. Dong, S. Hwang, D. Meyaard, E. Fred Schubert, Y. D. Han, J. W. Choi, J. Cho, and J. K. Kim, Appl. Phys. Lett. 103, 061104 (2013).

${ }^{6}$ E. F. Schubert, W. Grieshaber, and I. D. Goepfert, Appl. Phys. Lett. 69, 3737 (1996).

${ }^{7}$ I. D. Goepfert, E. F. Schubert, A. Osinsky, P. E. Norris, and N. N. Faleev, J. Appl. Phys. 88, 2030 (2000).

${ }^{8}$ J. K. Kim, E. L. Waldron, Y.-L. Li, T. Gessmann, E. F. Schubert, H. W. Jang, and J.-L. Lee, Appl. Phys. Lett. 84, 3310 (2004).

${ }^{9}$ S.-H. Yen, M.-C. Tsai, M.-L. Tsai, Y.-J. Shen, T.-C. Hsu, and Y.-K. Kuo, IEEE Photonics Technol. Lett. 21, 975 (2009).

${ }^{10}$ Z.-H. Zhang, Y. Ji, W. Liu, S. T. Tan, Z. Kyaw, Z. Ju, X. Zhang, N. Hasanov, S. Lu, Y. Zhang, B. Zhu, X. W. Sun, and H. V. Demir, Appl. Phys. Lett.104, 073511 (2014).

${ }^{11}$ Y. Ji, Z.-H. Zhang, Z. Kyaw, S. T. Tan, Z. G. Ju, X. L. Zhang, W. Liu, X. W. Sun, and H. V. Demir, Appl. Phys. Lett. 103, 053512 (2013).

${ }^{12}$ Z. G. Ju, W. Liu, Z.-H. Zhang, S. T. Tan, Y. Ji, Z. B. Kyaw, X. L. Zhang, S. P. Lu, Y. P. Zhang, B. B. Zhu, N. Hasanov, X. W. Sun, and H. V. Demir, Appl. Phys. Lett. 102, 243504 (2013).

${ }^{13}$ X. Ni, Q. Fan, R. Shimada, Ü. Özgür, and H. Morkoç, Appl. Phys. Lett. 93, 171113 (2008).

${ }^{14}$ C. H. Wang, S. P. Chang, W. T. Chang, J. C. Li, Y. S. Lu, Z. Y. Li, H. C. Yang, H. C. Kuo, T. C. Lu, and S. C. Wang, Appl. Phys. Lett. 97, 181101 (2010).

${ }^{15}$ K. Zhou, M. Ikeda, J. Liu, S. Zhang, D. Li, L. Zhang, J. Cai, H. Wang, H. B. Wang, and H. Yang, Appl. Phys. Lett. 105, 173510 (2014).
${ }^{16}$ F. Zhang, N. Can, S. Hafiz, M. Monavarian, S. Das, V. Avrutin, Ü. Özgür, and H. Morkoç, Appl. Phys. Lett. 106, 181105 (2015).

${ }^{17}$ S.-H. Han, C.-Y. Cho, S.-J. Lee, T.-Y. Park, T.-H. Kim, S. H. Park, S. W. Kang, J. W. Kim, Y. C. Kim, and S.-J. Park, Appl. Phys. Lett. 96, 051113 (2010).

${ }^{18}$ Z.-H. Zhang, S. T. Tan, Y. Ji, W. Liu, Z. Ju, Z. Kyaw, X. W. Sun, and H. V. Demir, Opt. Express 21, 15676 (2013).

${ }^{19}$ Y. Ji, Z.-H. Zhang, S. T. Tan, Z. G. Ju, Z. Kyaw, N. Hasanov, W. Liu, X. W. Sun, and H. V. Demir, Opt. Lett. 38, 202 (2013).

${ }^{20}$ R.-M. Lin, S.-F. Yu, S.-J. Chang, T.-H. Chiang, S.-P. Chang, and C.-H. Chen, Appl. Phys. Lett. 101, 081120 (2012).

${ }^{21}$ Z. Liu, J. Ma, X. Yi, E. Guo, L. Wang, J. Wang, N. Lu, J. Li, I. Ferguson, and A. Melton, Appl. Phys. Lett. 101, 261106 (2012).

${ }^{22}$ T. Lu, S. Li, C. Liu, K. Zhang, Y. Xu, J. Tong, L. Wu, H. Wang, X. Yang, Y. Yin, G. Xiao, and Y. Zhou, Appl. Phys. Lett. 100, 141106 (2012).

${ }^{23}$ Y.-K. Kuo, Y.-H. Shih, M.-C. Tsai, and J.-Y. Chang, IEEE Photonis Technol. Lett. 23, 1630 (2011).

${ }^{24}$ Z. Kyaw, Z.-H. Zhang, W. Liu, S. T. Tan, Z. G. Ju, X. L. Zhang, Y. Ji, N. Hasanov, B. Zhu, S. Lu, Y. Zhang, J. H. Teng, X. W. Sun, and H. V. Demir, Appl. Phys. Lett. 104, 161113 (2014).

${ }^{25}$ S. Nakamura, T. Mukai, M. Senoh, and N. Iwasa, Jpn. J. Appl. Phys., Part 2 31, L139 (1992).

${ }^{26}$ M. Lachab, D. H. Youn, R. S. Qhalid Fareed, T. Wang, and S. Sakai, Solid-State Electron. 44, 1669 (2000).

${ }^{27}$ J. Simon, V. Protasenko, C. Lian, H. Xing, and D. Jena, Science 327, 60 (2010).

${ }^{28}$ Z.-H. Zhang, S. T. Tan, Z. Kyaw, W. Liu, Y. Ji, Z. Ju, X. Zhang, X. W. Sun, and H. V. Demir, Appl. Phys. Lett.103, 263501 (2013).

${ }^{29}$ L. Zhang, K. Ding, J. C. Yan, J. X. Wang, Y. P. Zeng, T. B. Wei, Y. Y. Li, B. J. Sun, R. F. Duan, and J. M. Li, Appl. Phys. Lett. 97, 062103 (2010).

${ }^{30}$ Z.-H. Zhang, Z. Kyaw, W. Liu, Y. Ji, L. C. Wang, S. T. Tan, X. W. Sun, and H. V. Demir, Appl. Phys. Lett. 106, 063501 (2015).

${ }^{31}$ Z.-H. Zhang, W. Liu, S. T. Tan, Y. Ji, L. Wang, B. Zhu, Y. Zhang, S. Lu, X. Zhang, N. Hasanov, X. W. Sun, and H. V. Demir, Appl. Phys. Lett. $\mathbf{1 0 5}, 153503$ (2014).

${ }^{32}$ J. Piprek, Phys. Status Solidi A 207, 2217 (2010).

${ }^{33}$ V. Fiorentini, F. Bernardini, and O. Ambacher, Appl. Phys. Lett. 80, 1204 (2002).

${ }^{34}$ J. Piprek, R. K. Sink, M. A. Hansen, J. E. Bowers, and S. P. DenBaars, Proc. SPIE 3944, 28 (2000).

${ }^{35}$ S. M. Sze, Physics of Semiconductor Devices, 2 nd ed. (John Wiley \& Sons, Inc., 1981).

${ }^{36}$ H.- Y. Ryu and J.-I. Shim, Opt. Express 19, 2886 (2011).

${ }^{37}$ Z.-H. Zhang, S. T. Tan, W. Liu, Z. Ju, K. Zheng, Z. Kyaw, Y. Ji, N. Hasanov, X. W. Sun, and H. V. Demir, Opt. Express 21, 4958 (2013).

${ }^{38}$ S.-H. Han, D.-Y. Lee, S.-J. Lee, C.-Y. Cho, M.-K. Kwon, S. P. Lee, D. Y. Noh, D.-J. Kim, Y. C. Kim, and S.-J. Park, Appl. Phys. Lett. 94, 231123 (2009). 